\title{
Combined Treatment of Brain AVMs with Use of Onyx Embolization followed by Radiosurgery
}

\author{
L. Pierot, K. Kadziolka, F. Litré, and P. Rousseaux
}

\begin{abstract}
BACKGROUND AND PURPOSE: The treatment of cerebral AVMs is complex, reliant on interventions such as embolization, surgery, and radiosurgery, or a combination of these modalities. To date, treatment with the embolic agent Onyx, followed by radiosurgery, has not been evaluated. The goal of this study was to evaluate the safety and efficacy of this combination in a homogeneous, monocentric series.
\end{abstract}

MATERIALS AND METHODS: From April 2003 to June 2008, a total of 20 patients (11 women and 9 men; age range, 10-55 years) were treated for AVMs with Onyx embolization followed by radiosurgery. AVM sizes were $<3 \mathrm{~cm}$ in 7 patients and $\geq 3 \mathrm{~cm}$ in 13 patients. Modalities and complications of the procedure were analyzed as well as the long-term clinical and anatomic outcomes ( $2-5$ years after treatment).

RESULTS: Of 17 patients evaluated by DSA after radiosurgery, 10 (58.8\%) were observed to have complete occlusion of the AVM nidus. Complete occlusion was observed in 5 (71.4\%) of 7 Spetzler-Martin grade I-II AVMs and in 5 (50.0\%) of 10 Spetzler-Martin grade III-IV AVMs. Complete occlusion was observed in $4(80.0 \%)$ of 5 AVMs of $<3 \mathrm{~cm}$ and $6(50.0 \%)$ of 12 AVMs of $>3 \mathrm{~cm}$. One of 20 patients had significant worsening of clinical status ( $m R S \geq 2$ ) at long-term follow-up.

CONCLUSIONS: In this preliminary series, the safety and efficacy of combined treatment by Onyx embolization followed by radiosurgery are quite satisfactory, with a low rate of clinical complications (5.0\%) and a 58.8\% rate of complete obliteration of the AVM.

ABBREVIATIONS: $\quad$ DMSO = dimethyl-sulfoxide; $\mathrm{mRS}=$ modified Rankin Scale; $n$-BCA $=n$-butyl cyanoacrylate

C erebral AVMs are associated with significant morbidity and mortality related to intracerebral hemorrhage, seizures, and progressive neurologic decline. ${ }^{1}$ The treatment of cerebral AVMs can be quite complicated, and indication for treatment in some clinical situations is controversial (eg, for asymptomatic AVMs). Moreover, several modalities of treatment are available (surgery, radiosurgery, and embolization), and these modalities can be used in combination for some AVMs.

Several techniques are available for embolization, dependent on the embolization agent used and technique of microcatheterization. For many years, embolization with $n$-BCA has been standard clinical practice for the treatment of brain AVMs. In the last 10 years, $n$-BCA has been progressively replaced by Onyx (ev3, Irvine, California), a copolymer that precipitates when coming

Received June 26, 2012; accepted after revision September 28.

From the Departments of Neuroradiology (L.P., K.K.) and Neurosurgery (F.L., P.R.), Hôpital Maison-Blanche, CHU Reims, Reims, France.

Please send correspondence to Prof. Laurent Pierot, Service de Radiologie - Hôpital Maison-Blanche, 45, rue Cognacq-Jay, 51092 Reims Cedex; e-mail: Ipierot@gmail. com

http://dx.doi.org/10.3174/ajnr.A3409 into contact with blood. ${ }^{2-5}$ The progression of Onyx when injected into a brain AVM follows a lavalike flow pattern and is not associated with the risks of gluing the distal portion of the microcatheter as when using $n$-BCA. Onyx injections can be more prolonged and controlled compared with $n$-BCA, making it possible to occlude larger portions of the nidus during each injection.

The combination of embolization and radiosurgery is often used in the treatment of brain AVMs; however, the effectiveness of this combination remains controversial. Some series have suggested that embolization before radiosurgery was associated with lower obliteration rates and worse outcomes. ${ }^{6,7}$ Several mechanisms have been suggested to explain lower obliteration rates, including recanalization of the nidus after embolization, enhanced angiogenesis after embolization (as demonstrated in animal models), difficulty in delineation of the nidus after embolization, and beam attenuation by the liquid embolization material.

In most studies dedicated to the combination therapy of embolization followed by radiosurgery for the treatment of brain AVMs, particles or glue were used as the embolization agent. ${ }^{6,8,9}$ To our knowledge, no study to date has evaluated embolization with Onyx followed by radiosurgery. To very precisely evaluate

AJNR Am J Neuroradiol 34:1395-400 Jul 2013 www.ajnr.org

1395 
the combined therapy of Onyx embolization and radiosurgery, we conducted a monocentric, retrospective study, with all patients having very homogeneous modalities of treatment with embolization and radiosurgery.

\section{MATERIALS AND METHODS Patient Population}

All patients treated for brain AVMs in our department are prospectively included in a data base. In 2003, our department started using Onyx for AVM embolization. All patients treated by Onyx embolization and radiosurgery were included in our present series. To have a sufficient follow-up period after radiosurgery, we evaluated only patients treated by radiosurgery before June 2008 and did not exclude patients treated with both $n$-BCA and Onyx.

The following data were collected for every patient: sex, age, clinical presentation, and AVM location and size. Spetzler-Martin grade was calculated. ${ }^{10}$

The study was approved by the Institutional Review Board of Reims.

\section{Treatment Strategy}

Indications for treatment as well as modalities of treatment were defined on a multidisciplinary basis (neurologists, neurosurgeons, neuroanesthesiologists, and neuroradiologists). In brief, in the case of ruptured AVMs, surgery was performed emergently in the event of a compressive hematoma; in this situation, resection of the brain AVM was performed at the same time, if possible. In other ruptured AVMs, the choice of treatment was based on AVM anatomy (location, size, etc) and the patient's condition. Surgery and embolization were the first options because they are associated with an immediate result. When embolization was chosen as the first-line treatment, the first embolization session was usually performed at least 1 month after the bleeding event.

For ruptured AVMs, radiosurgery was used in selected cases as a complementary treatment in cases of incomplete treatment with surgery or embolization, or as first-line treatment if the AVM was untreatable by surgery or embolization.

For unruptured AVMs, indications for treatment were based on the balance between natural history and the risks associated with the treatment. Embolization was often used as the first-line treatment followed by radiosurgery in the case of incomplete embolization.

No treatment was performed when it was estimated that sufficient reduction of the AVM nidus would not be obtained by Onyx embolization to make radiosurgery feasible.

When embolization was selected as the first-line treatment, the goal was primarily to reduce the volume of the nidus as much as possible, with the objective being complete occlusion. If complete occlusion was not obtained by embolization alone, subsequent treatment was performed (surgery or radiosurgery).

Modalities of treatment were precisely explained to the patient and his or her family, and informed consent was obtained.

\section{Embolization Procedure}

Embolization treatment was performed as a staged treatment, with most cases requiring several sessions. The interval between sessions was approximately 6 weeks.
All procedures were performed with patients under general anesthesia by use of a biplane angiography system. A $6 \mathrm{~F}$ sheath was placed in the femoral artery and a $6 \mathrm{~F}$ guiding catheter inserted into the carotid artery or vertebral artery according to AVM anatomy. A flow-directed DMSO-compatible microcatheter (Marathon, UltraFlow, or Apollo; ev3) was navigated into the nidus. Superselective angiography was subsequently performed to precisely analyze the angioarchitecture of the nidus, the venous drainage, and to confirm the stable position of the microcatheter distal tip. Onyx was used as the first-line embolic agent except in the case of high-flow direct fistulas or when the microcatheter was inserted in a short feeding pedicle. In these circumstances, $n$-BCA was used.

For Onyx embolization, the microcatheter was flushed with normal saline, and the deadspace was filled with DMSO $(0.25$ $\mathrm{mL}$ ). Onyx was then slowly injected under subtracted fluoroscopic control. In the event of reflux or passage of Onyx in the draining veins, Onyx injection was interrupted for 30 seconds to 2 minutes and then restarted. At the end of the procedure, the microcatheter was removed by gentle traction.

Staged sessions of embolization were usually performed to progressively reduce the size of the circulating nidus and induce moderate nidal and perinidal changes to avoid hemorrhagic complications. During a session, embolization was usually interrupted after 1 hour or when approximately 5-mL volume of Onyx had been injected.

Treatment by embolization was interrupted when it was no longer possible to access the nidus or to inject Onyx into the nidus.

\section{Radiosurgical Procedure}

Radiosurgery was performed with a Leksell Gamma Knife Unit (Elekta, Norcross, Georgia). In all cases, radiosurgery was performed several weeks or months after AVM embolization to irradiate a hemodynamically stable AVM. The treatment target (residual nidus) was defined by $3 \mathrm{D}$ stereotactic $\mathrm{MR}$ imaging and DSA. The embolized nidus was usually not included in the radiation targeting. On the contrary, the origin of the draining veins was usually included in the radiation targeting.

\section{Follow-Up}

Patients underwent MR imaging every 6 months or 1 year. Control DSA was performed 3 years after radiosurgery but was sometimes advanced or delayed according to MR imaging results. If, after 3 years, the AVM was not completely obliterated, a multidisciplinary decision was made regarding further strategy of treatment.

We evaluated clinical status before and after treatment, and at the time of final DSA control (2-5 years after radiosurgery) by using the mRS scoring system (0: no symptoms; 1 : minor symptoms; 2: some restrictions in lifestyle; 3 : significant restrictions; 4: partially dependent; 5: fully dependent; 6: death).

\section{RESULTS}

\section{Patient Population}

A total of 20 patients (11 women and 9 men; age range, 10-55 years) were treated for a brain AVM by Onyx embolization fol- 


\begin{tabular}{|c|c|c|c|c|c|c|c|c|c|c|}
\hline \multirow[b]{2}{*}{$\begin{array}{l}\mathrm{Pt} \\
\text { No. }\end{array}$} & \multirow[b]{2}{*}{ Sex/Age } & \multirow[b]{2}{*}{ Presentation } & \multicolumn{3}{|c|}{ AVM } & \multicolumn{2}{|c|}{ Embolization } & \multicolumn{2}{|c|}{ Radiosurgery } & \multirow[b]{2}{*}{ Outcome } \\
\hline & & & $\begin{array}{c}\text { SM Grade } \\
\text { (I-IV) }\end{array}$ & $\begin{array}{l}\text { Size } \\
(\mathrm{cm})\end{array}$ & Location & $\begin{array}{l}\text { Sessions } \\
\text { (n) }\end{array}$ & $\begin{array}{c}\text { Onyx } \\
\text { Volume } \\
\text { (mL) }\end{array}$ & $\begin{array}{l}\text { Delay* } \\
\text { (month) }\end{array}$ & $\begin{array}{c}\text { Volume } \\
\text { Radiated } \\
(\mathrm{mL})\end{array}$ & \\
\hline 1 & $M / 35$ & Hemorrhage & 1 & $1.1 \times 0.7$ & Parietal & 1 & 0.25 & 6 & 0.6 & $\mathrm{CO}$ \\
\hline 2 & $\mathrm{~F} / 45$ & Asymptomatic & I & $1.2 \times 0.8$ & Temporal & 1 & 0.45 & 12 & 0.5 & $\mathrm{CO}$ \\
\hline 3 & $F / 55$ & Hemorrhage & I & $1.3 \times 1.2$ & Frontal & 1 & 1.0 & 16 & 0.6 & $\mathrm{RN}$ \\
\hline 4 & $M / 28$ & Hemorrhage & II & $2.5 \times 2.0$ & Frontal & 4 & 0.65 & 8 & 1.2 & $\mathrm{CO}$ \\
\hline 5 & $\mathrm{~F} / 15$ & Asymptomatic & II & $2.0 \times 1.2$ & Temporal & 4 & 2.65 & 36 & 0.9 & Ongoing \\
\hline 6 & $\mathrm{~F} / 12$ & SM deficit & II & $2.0 \times 1.3$ & Frontal & 2 & 3.2 & 8 & 3.0 & Ongoing \\
\hline 7 & $M / 42$ & Hemianopsia & II & $2.0 \times 1.0$ & Frontal & 3 & 3.35 & 6 & 0.9 & $\mathrm{CO}$ \\
\hline 8 & $M / 50$ & Asymptomatic & II & $3.8 \times 2.7$ & Temporal & 5 & 5.0 & 7 & 2.9 & $\mathrm{RN}$ \\
\hline 9 & $M / 28$ & Epilepsy & II & $4.2 \times 2.5$ & Frontal & 7 & 8.75 & 6 & 5.2 & Ongoing \\
\hline 10 & $\mathrm{~F} / 10$ & Epilepsy & II & $3.2 \times 1.5$ & Frontal & 5 & 2.45 & 7 & 1.1 & $\mathrm{CO}$ \\
\hline 11 & $F / 39$ & Motor deficit & III & $3.3 \times 1.7$ & Frontal & 2 & 1.7 & 5 & 7.8 & $\mathrm{CO}$ \\
\hline 12 & M/29 & Epilepsy & III & $3.9 \times 2.7$ & Frontal & 5 & 4.45 & 6 & 3.2 & $\mathrm{RN}$ \\
\hline 13 & $F / 26$ & Epilepsy & III & $3.1 \times 2.0$ & Frontal & 5 & 5.95 & 8 & 0.7 & $\mathrm{RN}$ \\
\hline 14 & $M / 41$ & Hemorrhage & III & $3.7 \times 1.1$ & Corpus callosum & 5 & 4.5 & 8 & 6.7 & $\mathrm{CO}$ \\
\hline 15 & $M / 25$ & Epilepsy & III & $3.9 \times 2.5$ & Temporal & 8 & 12.8 & 8 & 4.9 & $\mathrm{RN}$ \\
\hline 16 & $F / 45$ & Hemorrhage & IV & $3.4 \times 1.9$ & Temporal & 3 & 3.5 & 12 & 5.5 & $\mathrm{CO}$ \\
\hline 17 & $M / 23$ & Hemorrhage & IV & $4.0 \times 2.4$ & Frontal & 3 & 5.2 & 6 & 7.9 & $\mathrm{RN}$ \\
\hline 18 & $F / 37$ & Epilepsy & IV & $4.1 \times 1.9$ & Frontal & 5 & 6.5 & 6 & 5.3 & $\mathrm{CO}$ \\
\hline 19 & $\mathrm{~F} / 31$ & Hemorrhage & IV & $3.2 \times 2.3$ & Thalamus & 4 & 3.3 & 1 & 2.9 & $\mathrm{RN}$ \\
\hline 20 & $F / 49$ & Hemorrhage & IV & $3.9 \times 2.8$ & Frontal & 4 & 12.3 & 3 & 12.1 & $\mathrm{CO}$ \\
\hline
\end{tabular}

Note:-F indicates female; M, male; SM Spetzler-Martin grade; CO, complete occlusion; RN, residual nidus.

* Delay between embolization and radiosurgery.

lowed by radiosurgery from April 2003 to June 2008 (Table). Clinical presentation was hemorrhage in 8 patients, epilepsy in 6 patients, and progressive deficit in 3 patients. Three AVMs were asymptomatic.

Initial assessment (before any treatment) showed that AVM Spetzler-Martin grade was I in 3 patients, II in 7 patients, III in 5 patients, and IV in 5 patients. AVM size was $<3 \mathrm{~cm}$ in 7 patients and $\geq 3 \mathrm{~cm}$ in 13 patients. No AVM was greater than $6 \mathrm{~cm}$. Location of the AVM was the frontal lobe in 12 patients, the temporal lobe in 5 patients, the parietal lobe in 1 patient, the thalamus in 1 patient, and the corpus callosum in 1 patient.

\section{Modalities of Treatment}

For all patients, the multidisciplinary neurovascular local group decided that, according to the clinical presentation and the anatomic characteristics of the AVM, surgery was not indicated. The treatment strategy was to start with Onyx embolization sessions to reduce the size of the nidus as much as possible or to cure it. If there was incomplete occlusion of the nidus, the decision was to complete the treatment with radiosurgery.

The number of embolization sessions was 1 in 3 patients, 2 in 2 patients, 3 in 3 patients, 4 in 4 patients, 5 in 6 patients, and more than 5 in 2 patients ( 7 and 8 sessions). All patients were exclusively or partially treated with Onyx. Five patients were partially treated with glue. In 1 patient, treatment was started before Onyx was available in our department. In 3 patients, $n$-BCA was used to treat high-flow direct fistulas. In 1 patient, $n$-BCA was used after AVM rupture during microcatheterization (see below). The total volume of Onyx injected (cumulated sessions) was 0.25 to 12.8 $\mathrm{mL}$ (mean, $4.4 \mathrm{~mL}$ ).

For all patients in whom the treatment strategy was predefined as embolization followed by radiosurgery, radiosurgery was effectively performed after completion of the embolization sessions. If the residual nidus evaluated by MR imaging/MR angiography and DSA was considered too large for radiosurgery, further reduction by embolization was discussed.

Radiosurgery was performed 1 to 36 months after the last embolization session. The delay for radiosurgery was $<6$ months in 3 patients (1,3, and 5 months, respectively), 6-8 months in 13 patients, and $>8$ months in 4 patients ( 12 months in 2 patients, 16 months in 1 patient, and 36 month in 1 patient). The volume of radiated nidus was between 0.5 and $12.1 \mathrm{~mL}$.

\section{Anatomic Results}

Anatomic results were not evaluated by DSA in 3 patients. Two patients were lost to follow-up. One patient refused control DSA.

Of 17 patients evaluated by DSA after radiosurgery, 10 had complete occlusion of the AVM nidus (Fig 1). Complete occlusion was depicted by DSA performed at 2 years in 2 patients, 3 years in 4 patients, 4 years in 2 patients, and 5 years in 2 patients.

Residual nidus was depicted at 3 years in 3 patients and at 4 years in 4 patients. Residual nidus was treated by Onyx embolization and radiosurgery in 2 patients and radiosurgery alone in 3 patients. In 2 patients, another control angiogram will be performed after 1 year.

Complete occlusion was observed in $5(71.4 \%)$ of 7 SpetzlerMartin grade I-II AVMs and in 5 (50.0\%) of 10 Spetzler-Martin grade III-IV AVMs. Complete occlusion was observed in 4 $(80.0 \%)$ of $5 \mathrm{AVMs}<3 \mathrm{~cm}$ and $6(50.0 \%)$ of $12 \mathrm{AVMs}>3 \mathrm{~cm}$.

\section{Complications and Clinical Status}

Intraoperative rupture was observed in 2 patients, during catheterization in 1 patient (immediately treated by glue injection), and after Onyx injection in 1 patient. No clinical modification was observed in the first patient. Transient worsening of a pre-existing deficit was observed in the other patient. 

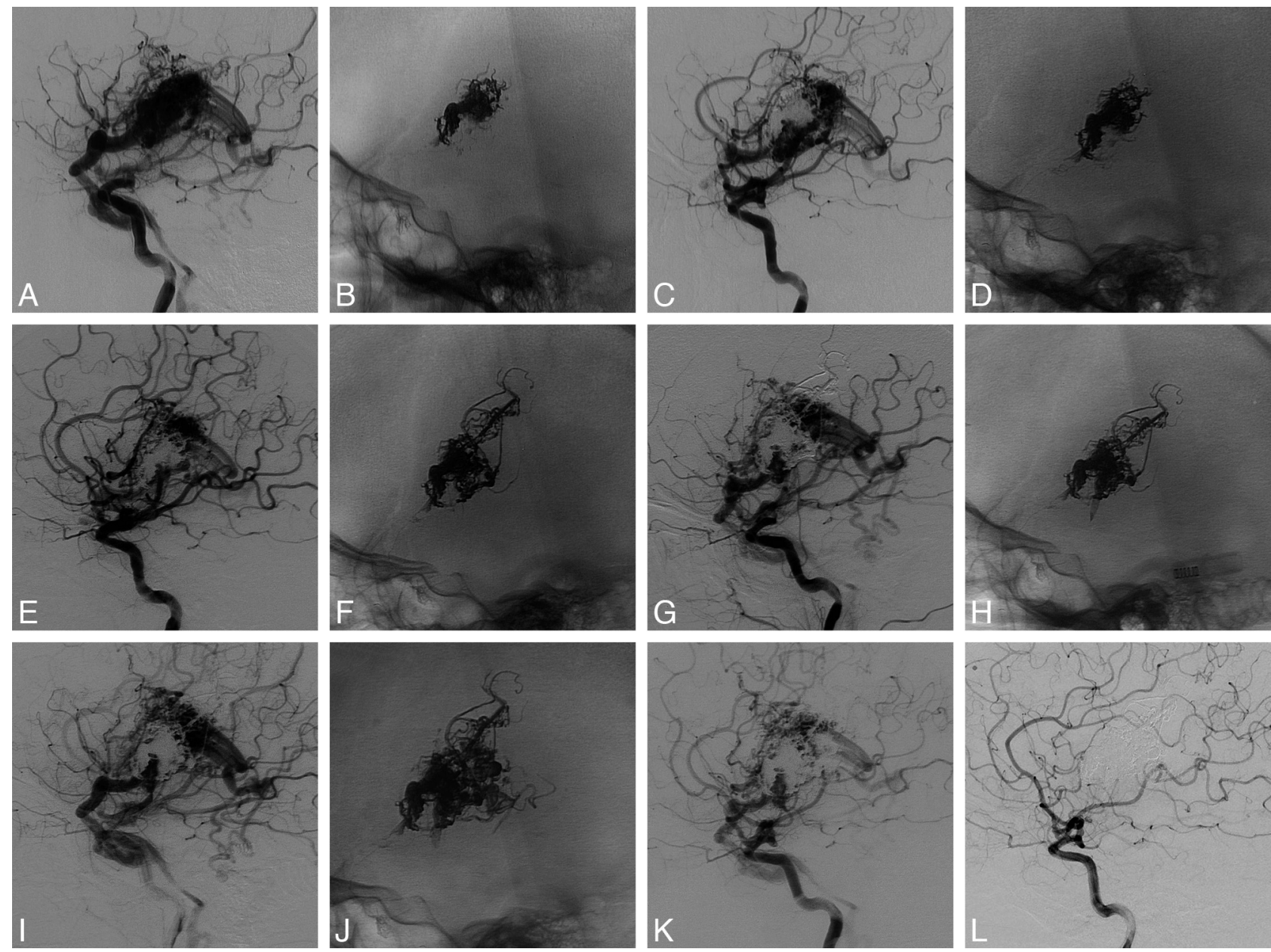

FIG 1. Left frontal AVM. A, Left internal carotid angiogram (lateral view) shows the AVM before treatment. B, Onyx cast after the first embolization session. C, Left internal carotid angiogram (lateral view) shows the AVM after the first embolization session. D, Onyx cast after the second embolization session. E, Left internal carotid angiogram (lateral view) shows the AVM after the second embolization session. $F$, Onyx cast after the third embolization session. G, Left internal carotid angiogram (lateral view) shows the AVM after the third embolization session. $H$, Onyx cast after the fourth embolization session. I, Left internal carotid angiogram (lateral view) shows the AVM after the fourth embolization session. J, Onyx cast after the fifth embolization session. $K$, Left internal carotid angiogram (lateral view) shows the AVM after the fifth embolization session. L, Left internal carotid angiogram (lateral view) shows complete cure of the AVM at 5 years after radiosurgery.

Three patients had transient deficit (without hemorrhage) after 1 session of embolization. Two patients had partially regressive deficit after 1 embolization session. Of these, 1 had hemiparesis with favorable evolution, and 1 had hemiparesis and aphasia with complete recovery of hemiparesis but only partial recovery of aphasia. This deficit was the result of a thromboembolic complication.

Clinical status was permanently worsened by embolization in 2 patients $(10.0 \%)$, with a final $\mathrm{mRS}$ score of 1 in 1 patient and 2 in 1 patient. No clinical modification was observed due to radiosurgery. No deaths and no intracranial hemorrhages were observed during the follow-up period.

Pretreatment mRS score was 0 in 18 patients. Preoperatively, 1 patient had an mRS score of 1 (hemiparesis related to basal ganglia bleeding), and another patient had an mRS score of 2 (aphasia related to a pretreatment stroke). Posttreatment mRS was 2 in 2 patients, with an initial mRS score of 0 related to embolization complications. Of these, 1 patient showed good recovery with a final mRS score of 1 at the final clinical evaluation.

Final clinical evaluation was mRS score of $0-1$ in 18 patients and 2 in 2 patients (pre-existing to treatment in 1 patient). Significant modification of the clinical status $(\mathrm{mRS} \geq 2)$ was observed in only 1 patient $(5.0 \%)$.

\section{DISCUSSION}

The treatment of brain AVMs is often complex and is frequently performed by use of a combination of treatment modalities. One common treatment combination is embolization followed by radiosurgery. Several years ago, embolization was mostly performed by using glue, but the effectiveness of this embolization agent is limited because it can only be injected during a relatively short duration that limits the nidus volume occluded per injection. The advantage of Onyx is that it is a precipitating agent rather than a polymerizing agent. This allows for longer injection durations and makes it possible to achieve better occlusion of the nidus in 1 injection.

The use of Onyx is associated with an increasing number of AVMs cured by embolization alone. ${ }^{2,4,11}$ In our initial series of brain AVMs treated with Onyx, the percentage of brain AVMs cured by embolization alone was $8.3 \% .^{2}$ Several years later, this 
percentage has increased to $23.5 \%$ in the entire population of brain AVMs and $36.7 \%$ for brain AVMs whose size is $<3$ $\mathrm{cm}^{11}$ However, complete anatomic cure is not always obtained with Onyx embolization alone, and a complementary treatment is sometimes necessary. Previous reports have shown that surgery is feasible after Onyx embolization, but controversy prevails regarding the efficacy of radiosurgery after embolization. ${ }^{12}$ In 2007, Andrade-Souza et $\mathrm{al}^{6}$ reported a series of 47 patients treated by glue embolization followed by radiosurgery. This group was compared with a matching group of 47 patients treated exclusively by radiosurgery. The data from this series suggested that embolization before radiosurgery was associated with a lower obliteration rate $(47 \%$ compared with $70 \%$ in patients treated exclusively by radiosurgery). More recent series dealing with the treatment of brain AVMs by embolization followed by radiosurgery showed higher rates of nidus obliteration. Zabel du Bois et $\mathrm{al}^{8}$ reported complete obliteration in 67\% of patients at 3 years and $78 \%$ at 4 years for AVMs treated with Histoacryl (Braun, Melsungen, Germany) embolization and radiosurgery. Recently, Blackburn et $\mathrm{al}^{9}$ showed that staged en-

dovascular embolization with Histoacryl followed by stereotactic radiosurgery provides an effective means to treat large AVMs $(>3$ $\mathrm{cm}$ ), obtaining a high rate of AVM obliteration after this combined treatment $(81 \%)$. In our series, the rate of complete obliteration after Onyx embolization and radiosurgery is in a similar range as in series of patients treated with Histoacryl embolization and radiosurgery $(58.8 \%)$. In a recent series dealing with 86 patients treated with Onyx embolization, complete occlusion was obtained by embolization alone in 16 patients $(18.5 \%) .{ }^{13}$ Fortyeight patients were treated by embolization and radiosurgery, and 23 of 30 patients with 3-year follow-up DSA had complete obliteration $(76.7 \%)$.

Comparing our results with radiosurgical series is difficult because the populations of patients are different from one series to another according to AVM size (or volume) and to other anatomic factors, as well as therapeutic factors (linear accelerator/ gamma knife, radiation strategy, dose, etc). In one of the most recent series dealing with gamma knife treatment, the rate of 6-year AVM obliteration was $71.4 \%$, which is relatively close to our rate, considering that most of our patients were evaluated at 3 or 4 years. ${ }^{14}$

In our series, complete occlusion was more frequently obtained in grade I-II AVMs compared with grade III-IV AVMs (71.4\% and 50\%, respectively). In fact, the critical factor is likely AVM size with a higher rate of obliteration in AVMs $<3 \mathrm{~cm}$
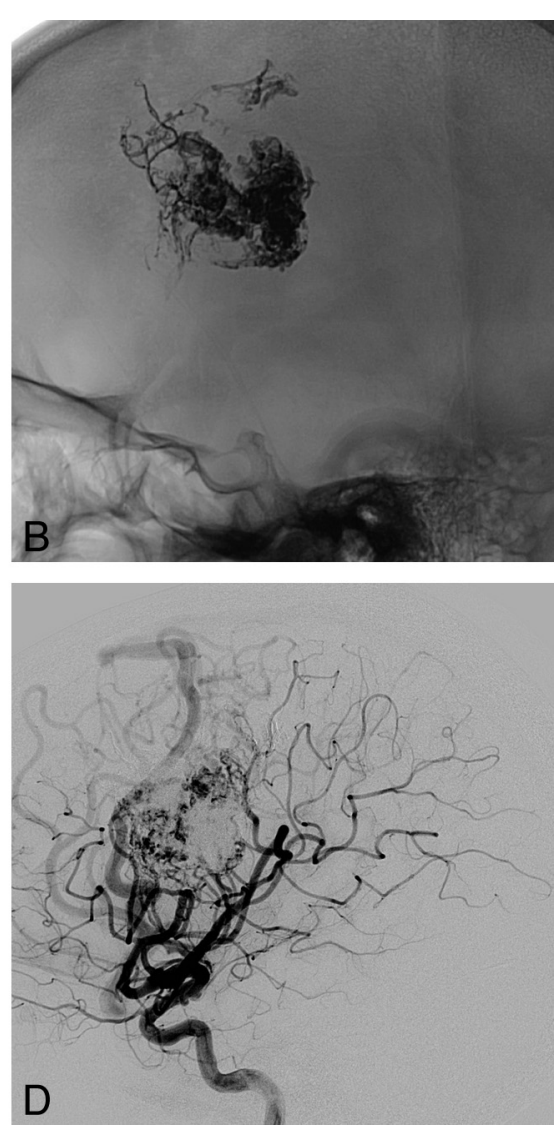

D

FIG 2. Right frontal AVM. A, Right internal carotid angiogram (lateral view) shows the AVM before treatment. $B$, Right internal carotid angiogram, noninjected and unsubstracted (lateral view), shows the Onyx cast after 5 embolization sessions and before radiosurgery. $C$, Right internal carotid angiogram shows the residual nidus before radiosurgery. $D$, Right internal ca(80.0\%) compared with AVMs $\geq 3 \mathrm{~cm}(50.0 \%)$. Similar results were reported by Zabel du Bois et $\mathrm{al}^{8}$ : complete obliteration was $90 \%$ in AVMs grade I-II and 59\% in AVMs grade III-IV, and $92 \%$ in AVMs $<3 \mathrm{~cm}$ and $60 \%$ in AVMs $\geq 3 \mathrm{~cm}$.

Several potential problems can be encountered when radiosurgery is performed after Onyx embolization. The delineation of the target for radiosurgery is potentially difficult because of fragmentation of the nidus by the previous embolization and MR and CT artifacts related to the presence of Onyx during the scan. To avoid the potential risk of having multiple small residual nidi, our strategy for embolization is to progressively occlude adjacent nidal portions as much as possible. This means that the selection of arterial pedicles for embolization is critical, and it should be made in such a way that homogeneous nidal occlusion is obtained. If Onyx is producing significant MR and CT artifacts, radiosurgical treatment planning is a critical step, and modified inhomogeneity corrections must be introduced to improve the results. ${ }^{15}$

In their publication, Andrade-Souza et $\mathrm{al}^{6}$ suggested that glue deposited in the nidus can attenuate the dose applied by radiosurgery to the AVM by as much as $10 \%-15 \%$. Recent studies, however, demonstrate that prior embolization with $n$-BCA or Onyx does not significantly reduce the target dose to brain AVMs treated with gamma knife radiosurgery. ${ }^{16}$ Another potential problem in AVMs treated with embolization and radio- 
surgery is recanalization of the embolized AVM compartments; however, recanalization was mainly observed in the case of particulate embolization or when the feeding pedicle and not the nidus was occluded by the embolic agent. Intranidal injection of glue or Onyx is probably the appropriate way to avoid late recanalization of embolized compartments.

In our series, the global clinical outcome 2-4 years after embolization and radiosurgery was quite satisfactory. A worsening of the clinical status with a $\mathrm{mRS} \geq 2$ was observed permanently in only 1 case $(1 / 20$ [5.0\%]), and this was related to a thromboembolic complication that occurred during a session of embolization. No bleeding and no deaths were observed in this series. In their very large series of patients treated with Onyx embolization, Saatci et $\mathrm{l}^{4}$ also reported low morbidity and mortality rates $(7.1 \%$ and $1.4 \%$, respectively). Blackburn et $\mathrm{al}^{9}$ also reported good clinical outcome after combined treatment by embolization and radiosurgery in 21 patients with large AVMs ( $0 \%$ mortality, $0 \%$ major permanent neurologic morbidity, 20\% permanent minor neurologic morbidity). In the series reported by Andrade-Souza et al, ${ }^{6}$ excellent outcome (complete obliteration of the nidus and no deficit) was more frequent in patients treated with radiosurgery alone (64\% vs $47 \%$ in patients treated with embolization and radiosurgery), but the clinical outcome was not analyzed separately.

Our strategy of treatment, singularly in cases of ruptured AVMs but also in unruptured AVMs, is to use therapeutic modalities that will provide an immediate occlusion of the AVM (surgery or embolization). When surgery is difficult, impossible, or potentially associated with clinical worsening, the next option will be embolization. Radiosurgery is used in combination with Onyx embolization when embolization alone will not succeed in obtaining total obliteration of the nidus or as part of a preplanned therapeutic association (singularly in front of large AVMs). Radiosurgery can also be used as the only treatment when the nidus is small and difficult to approach by the endovascular approach.

Our study had several limitations. One limitation was that our series was monocentric and retrospective, with a small patient population (20 patients with 3 years or more of DSA follow-up in 17 patients). The goal, however, was to analyze a population of patients treated in a homogeneous way, with a standardized technique of Onyx embolization and a homogeneous technique for radiosurgery. A second limitation of our study is that 2-4 years of follow-up DSA were not obtained for all patients. Contrary to other studies, we chose not to use MR imaging/MR angiography to evaluate anatomic results, as our personal experience is that these techniques may lead to a false diagnosis of complete occlusion. A third limitation was that, because our study was describing a relatively small population of patients treated in a homogeneous way, it was not possible to answer important and relevant questions, such as efficacy of radiosurgery alone in small AVMs, appropriate AVM volume reduction by embolization for optimal radiosurgery, respective value of Onyx and glue in preradiosurgical embolization, and optimal targeting and dosimetry for radiosurgery.

\section{CONCLUSIONS}

In this preliminary series of patients with AVMs treated with Onyx embolization followed by radiosurgery, the safety and efficacy of this treatment combination were quite satisfactory, with a
$58.8 \%$ rate of complete obliteration and a low rate of clinical complications (5.0\%). This treatment combination can be proposed for the treatment of brain AVMs when a single-technique treatment is not feasible or as an alternative treatment to embolization followed by surgery, especially in cases of unruptured AVMs.

Disclosures: Laurent Pierot—RELATED: Consulting Fee or Honorarium: eV3/Covidien; Support for Travel to Meetings for the Study or Other Purposes: eV3/Covidien; UNRELATED: Consultancy: Codman, MicroVention, Penumbra, Sequent, Stryker.

\section{REFERENCES}

1. Cognard C, Spelle L, Pierot L. Pial arteriovenous malformations. In: Forsting M, ed. Intracranial Vascular Malformations and Aneurysms. Berlin: Springer-Verlag; 2004:39-100

2. Pierot L, Januel AC, Herbreteau D, et al. Endovascular treatment of brain arteriovenous malformations using Onyx: results of a prospective, multicenter study. J Neuroradiol 2009;36:147-52

3. Loh Y, Duckwiler GR, for the Onyx Trial Investigators. A prospective, multicenter, randomized trial of the Onyx liquid embolic system and N-butyl cyanoacrylate embolization of cerebral arteriovenous malformations. Clinical article. J Neurosurg 2010;113:733-41

4. Saatci I, Geyik S, Yavuz K, et al. Endovascular treatment of brain arteriovenous malformations with prolonged intranidal Onyx injection technique: long-term results in 350 consecutive patients with completed endovascular treatment course. J Neurosurg 2011; 115:78-88

5. Pan JW, Zhou HJ, Zhan RY, et al. Supratentorial brain AVM embolization with Onyx-18 and post-embolization management. A single-center experience. Interv Neuroradiol 2009;15:275-82

6. Andrade-Souza YM, Ramani M, Scora D, et al. Embolization before radiosurgery reduces the obliteration rate of arteriovenous malformations. Neurosurgery 2007;60:443-51; discussion 451-52

7. Back AG, Vollmer D, Zeck O, et al. Retrospective analysis of unstaged and staged gamma knife surgery with and without preceding embolization for the treatment of arteriovenous malformations. J Neurosurg 2008;109 Suppl:57-64

8. Zabel du Bois A, Milker-Zabel S, Huber P, et al. Risk of hemorrhage and obliteration rates of LINAC-based radiosurgery for cerebral arteriovenous malformations treated after prior partial embolization. Int J Radiation Oncology Biol Phys 2007;68:999-1003

9. Blackburn SL, Ashley WW Jr, Rich KM, et al. Combined endovascular embolization and stereotactic radiosurgery in the treatment of large arteriovenous malformations. J Neurosurg 2011; 114:1758-67

10. Spetzler RF, Martin NA. A proposed grading system for arteriovenous malformations. J Neurosurg 1986;65:476-83

11. Pierot L, Casasco A, Cognard C, et al. Embolisation des MAV cérébrales à l'Onyx: résultats de l'étude BRAVO. J Neuroradiol 2011; 38:11

12. Weber W, Kis B, Siekmann R, et al. Preoperative embolization of intracranial arteriovenous malformations with Onyx. Neurosurgery 2007;61:244-52; discussion 252-54

13. Xu F, Ni W, Liao Y, et al. Onyx embolization for the treatment of brain arteriovenous malformations. Acta Neurochir (Wien) 2011; 153:869-78

14. Douglas JG, Goodkin R. Treatment of arteriovenous malformations using gamma knife surgery: the experience at the University of Washington from 2000 to 2005. J Neurosurg 2008;109 Suppl:51-56

15. Shtraus N, Schifter D, Corn BW, et al. Radiosurgical treatment planning of AVM following embolization with Onyx: possible dosage error in treatment planning can be averted. J Neurooncol 2010;98:271-76

16. Mamalui-Hunter M, Jiang T, Rich KM, et al. Effect of liquid embolic agents on gamma knife surgery dosimetry for arteriovenous malformations. Clinical article. J Neurosurg 2011;115:364-70 